\title{
Information Disclosure in Social Media among Teenagers
}

\author{
Norhayati Hussin, Nurul Nabila Azli, Ahmad Zam Hariro
}

\begin{abstract}
Social Media is a platform where people can communicate with each other easily without any boundaries. Teenagers tend to used social media to disclose information such as email, pictures and location. In Malaysia, the number of cyberbully and suicide because of social media keep increasing. Thus, this study was about the information disclosure in social media among teenagers in Malaysia. The purpose of this study was to determine the factors that influence information disclosure in social media among teenagers in Malaysia. It has been found that factors enjoyment, perceived usefulness and trust were the factors that influence teenagers to disclose information in social media. This study used a quantitative research method and questionnaire were distributed to 335 students at Sekolah Menengah Kebangsaan Rantau Panjang Klang. It was found that there was a relationship between independent variables (Enjoyment, Perceived Usefulness and Trust) and the dependent variable (Information Disclosure). From the finding, it has been found that Trust is the most influential factor in information disclosure in social media among teenagers in Malaysia where, when people trust their member in social media it influences them to disclose more information in social media.
\end{abstract}

Keywords : Information Management, Information disclosure, Enjoyment, Perceived Usefulness, Trust.

\section{INTRODUCTION}

Social Networks Sites (SNS) such as Facebook, Instagram, Twitter, blogs and WhatsApp were medium that connecting and enabling users to communicate with others (Raghavan, 2006). Users used social media as a platform to share their ideas, personal message, information and other content like picture and videos. The advent of social media nowadays tends people to disclose their information voluntarily. For example, the user shared their personal information such as birth dates and location. According to McKnight, Lankton, and Tripp (2011), information disclosure in this sense means the level to which one lets access to aspects of one's personal information, rather than the more traditional meaning of whether or not one share's personal information. In Malaysia, the statistic of internet users is kept increasing wherein 2015 growth $11 \%$ from

Revised Manuscript Received on October 15, 2019.

* Correspondence Author

Norhayati Hussin, Faculty of Information Management, Universiti Teknologi MARA, UiTM Selangor, Malaysia.

Nurul Nabila Azli, Faculty of Information Management, Universiti Teknologi MARA, UiTM Selangor, Malaysia.

Ahmad Zam Hariro, Faculty of Information Management, Universiti Teknologi MARA, UiTM Selangor, Malaysia.
$66.6 \%$ in 2014 which $14.6 \%$ per cent of Malaysian teenagers used internet where it indicates that teenagers are the second larger users of social media in Malaysia which $80 \%$ of users used the internet for social media (MCMC, 2016). Since teenagers are willing to disclose their information in social media without boundaries, there are must be the factors influencing teenagers in revealing the news in social media.

In this globalisation era, the internet was the most important things in our daily life and Social Networking Sites (SNS) or known as Social Media nowadays become principal of the communications tools. Research from Bazarova \& Choi (2014) states that social media give benefits to build a relationship with others. However, there were the risks of using social media that provide a problem to the users such as cyberbully (Marwick and Boyd, 2011). In Malaysia, cyberbully among teenagers is become critical issues and always be talked in Malaysian newspaper Simon (2007) which it effects the on their psychology (Thye, 2017). This is because nowadays are more easy voicing their emotions online where it allows them to hide behind a virtual mask (Pillay, 2017) which for them it is more convenient, less embarrassing and more ease. According to Dr Ong Beng Keat (2017), the statistic of suicides in Malaysia has increased by leaps and bounds in recent years because of social media. Since social media was a medium to disclose the information easily, and it gives serious issues in Malaysia. Therefore, it is important to know the intention of teenagers used social media to disclose their information where there is no study regarding on Information disclosure in Social Media among Teenagers in Malaysia.

This study was concentrate on teenagers in Malaysia since this group were the second higher users in social media in Malaysia. The sample of this study were students from Sekolah Menengah Kebangsaan Rantau Panjang Klang because they were teenagers group where their age between 13 and 17 which according to Daud (2014), the age of teenager was between 12 years old to 19 years

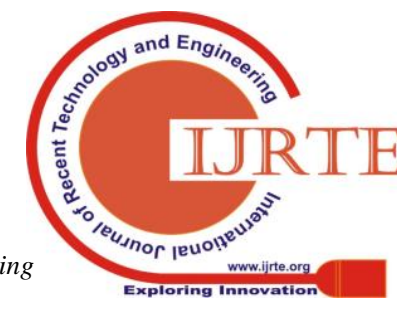


old. School in Klang Valley been chosen as a sample because, in this area, there has great exposure in social media due to the greater coverage of the internet.

\section{OVERVIEW OF INFORMATION DISCLOSURE}

Researchers have focused on concerns about teenager's safety on the Social Media. Social Media privacy problems can stem from the interplay three factors, which include what type of Social Media security capabilities provided, what personally identifiable information of the users of Social Media disclose and what particular end user data on Social Media is sought out and used by third parties. For example, teenagers consciously and unconsciously reveal their information to people they do not know and actually would not trust to access to that information they made available and maybe this information being used unexpected and a harmful way. Elmi, A. Iahad, and Ahmed (2013) states that there are many documented cases of Social Media accessed by marketing organisations, employers, university official and others, resulting in difficulties for a student who disclosed information without any consequences.

EDUCAUSE Centre for Applied Research (ECAR) has found that information revelation issues by asking students who use Social Media on what access limitation they place on their profile. They also found that usually, all age group will include their photos and first name in their profile. Most of them include their last name, email address, and handphone number. Furthermore, the first step to participating in social media is by disclosing information. To create an account such as Facebook, Twitter, Instagram and other social media account, the user needs to provide personal information such as interest, date, and place of birth, email, and location. By uploading photos and updating status, social media users disclose the enormous amount of their personality and disclosing personal information will be continuous.

According to Jourard (1971), the disclosure is the act of people revealing their personal information to others. Disclosing personal information about oneself is also known as self-disclosure. Self-disclosure also has been defined as confidentiality interchange when users give (or perceive) a value or reward for disclosing personal information and act contrarily to privacy behaviour (Jiang, Heng, and Choi, 2013). In other research by McKnight, Lankton, and Tripp (2011), they stated that information disclosure could be defined as the degree of people give access to others for their personal information. In a social media context, disclosing information is include given on the profile, and the communicative actions users perform (Zlatolas,
2015). This is because, by involving in social media, social media's users will update their status, share location, like or comment with other which they normally will provide their personal information. This is in line with the definition described by Krasnova and Veltri (2010), where self-disclosure or information disclosure is any message about the personality that an individual communicates with others. This study uses the terms of self-disclosure and information disclosure to describe any form of personal information that an individual provides on Social Media.

Numerous terms are used to describe information disclosure the most common of information disclosure is the act where people share or reveal their personal information with other. The conclusion from the statement of definition from previous studies, information disclosure, is exposed information to other parties intentionally. In this research, the terms of information disclosure to describe the behaviour of people disclosed their personal information on social media.

According to Hart, Ridley, Taher, Sas, and Dix (2008), social media mostly exits for connecting with sharing information with friends: a user may weigh the costs and benefits of information disclosure. Taking into this account where people used social media to build the network with others and to interact with others. People develop a relationship in social media, and they are willing to disclose their information which it turns to reduce privacy (Altman, 1975). Information privacy can be defined as the ability to control personal information when it been shared with other entity (Dienlin and Metzger, 2016). Based on the previous studies, information privacy significant with information disclosure whereby people willing to have information sharing to foster the relationship in social media. According to Laufer and Wolfe (1977), during information exchange, user's private behaviour is determined by a privacy calculus. Privacy calculus is when user consider the aspects of cost and benefits that will influence them to disclose personal information or not (Krasnova, Spiekermann, Koroleva, and Hildebrand, 2010). Applying to this study, since social media is a platform to communicate, privacy calculus is relevant to be used to know the factors that influence people to disclose information. Individuals have the purpose of disclosing their information because of the benefits versus risk of disclosure (McKnight et al., 2011). This statement was also supported by the previous study by Culnan and Armstrong (1999), people have a strong belief in the cost and benefits of information disclosure simultaneously. According to 
(Svenja, 2016) people weigh the benefits of social media as more important than the possible loss of privacy(cost). People will disclose their information and accept the risk when they perceived more benefits than risk.

Most of the research found that factor of benefits element was positively influenced in information disclosure or self-disclosure compared with cost element which was the most negative impact on information disclosure, to conduct this research benefits element is used to achieve the objective of this study. Enjoyment, Perceived usefulness, and Trust are the factors influencing Information Disclosure in this study.

\section{FACTOR INFLUENCING INFORMATION DISCLOSURE}

\section{Enjoyment}

According to Heijden (2004), enjoyment is earnings positive, hedonic sense one has when doing something, apart from any estimated performance consequences. Research by Hart, Ridley, Taher, Sas, and Dix (2008) states that enjoyment was the main reason people used Social Media. Krasnova (2009); Elmi, A. Iahad, and Ahmed (2013); McKnight, Lankton, and Tripp (2011) states that enjoyment can rise self-disclosure in social media. Hogben mentioned a sense of connectedness, self-enhancement, and possibility to interact and share experiences with like-minded individuals as possible benefits of Social Media. For instance, users may find it pleasurable to know that others can see their activities and interests. Thus, Social Media such as Facebook or Twitter, are organised and presented in a way that enables pleasurable user experiences so that users participate and self-communicate more. The more the Social Media users experience enjoyment, the more user will contribute to information disclosure activity.

\section{Perceived Usefulness}

Sharing information with other users makes a Social Media website such as Facebook, Instagram and Twitter more productive and effective in social media activities. Research by Sun, Wang, Shen, and Zhang (2015); Li and Sarathy (2007) found that usefulness was the benefits factor that will influence the intention of Social Media's users to disclose their information. A study by David (1989) where he states that perceive usefulness is the essential dimension that determines the behavioural intention to adopt a technology. Retracting access to personal information could hamper this usefulness. The more useful a Social Media is the more offset risks and thus encouraging users to disclose their information. Hence, this study predicts that usefulness will increase information disclosure among teenagers.

\section{Trust}

The trust factor plays a vital role in revealing private information in Social Media. Trust can be defined as the willingness to accept a vulnerable situation based on positive expectation regarding the action of others (Mesch, 2012). Thus, users might rely on the Social Media provider not to abuse their information for its personal gain. The context of trust has two dimensions. The first dimension is the user trust other community members not misuse the thought, life experiences and other sensitive information that they share. The second dimension is individual Social Media member trust the providers of these sites to secure their data. In this study, it was selected only in exploring the trust on Social Media's users to Social Media's members. Trust in Social Media Members reflects an individual belief in others users' non-opportunistic behaviour, benevolence, and trustworthiness (Chiu, Hsu, \& Wang, 2006). The one who trust their members in Social Media well feel the site will be more desirable and less risky to use. Research in the USA by McKnight, Lankton, and Tripp (2011) has found that trust is the factor that rises disclose in Social Media among the users. Thus, the more the trust in member on Social Media, the more useful is likely to continue intention to disclose their information in Social Media (Veltri, Krasnova, \& Garah, 2011).

\section{RESEARCH FRAMEWORK}

Figure 1 shows the theoretical framework about the research topic regarding the factors influences the information disclosure in social media. The proposed framework was adapted from Elmi, A. Iahad, and Ahmed (2013), McKnight, Lankton, and Tripp (2011) and Krasnova, Kolesnikova and Gunther (2009). Enjoyment, Perceived Usefulness and Trust are the independent variables that influence the Information Disclosure which is the dependent variable. Based on the previous research, these three dependent variables have a relationship with information disclosure. Thus the proposed framework consists of this three independent variable and dependent variable.

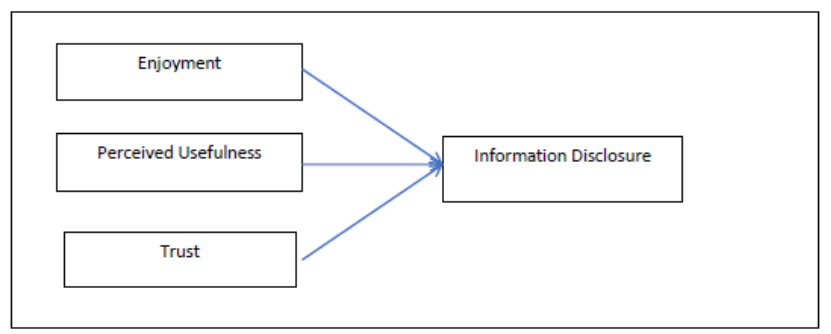




\section{Hypotheses}

Hypothesis 1: Enjoyment has a relationship with information disclosure in Social Media among teenagers in Malaysia

Hypothesis 2: Perceived Usefulness has a relationship with information disclosure in Social Media among teenagers in Malaysia

Hypothesis 3: Trust has a relationship with information disclosure in Social Media among teenagers in Malaysia

\section{METHODOLOGY}

This study employed a survey method using questionnaires as the instrument. The samples of this study were students at Sekolah Menengah Kebangsaan Rantau Panjang, Klang, Malaysia. Self-administered questionnaires were distributed randomly to 335 student selected students who study in Sekolah Menengah Kebangsaan Rantau Panjang Klang and the return rate was $n=335(100 \%)$. The questionnaires were adapted from Krasnova, Kolesnikonova, and Gunther (2009), Veltri, Kosnova, and Garah (2011) and McKnight, Lankton, and Tripp (2011) regarding on the topic of Information Disclosure. For data analyses, descriptive statistical analysis was performed using the Statistical Package of Social Science (SPSS).

\section{FINDINGS}

\section{Profile of Respondents}

The distribution of respondents by gender shows that (188 or $56 \%$ ) of them were Female and other (147 or $44 \%$ ) were Male. Respondents within age 17 - 19 years old form largest group (230 or $68.7 \%$ ) followed by respondents at the age between 14 - 16 years old (99 or $29.6 \%$ ). The lowest of respondents ( 6 or $1.7 \%$ ) were made up of those who were between 11 - 13 years old.

All of the respondents have a Social Media account, and 242 respondents have actively use the Instagram account. This made up the largest proportion from a sample collected, which is at $72.2 \%$. Followed by Facebook with 66 respondents, at $19.7 \%$ and Twitter, constituting $5.4 \%$ respondents. Only 9 respondents record another Social Media account. The frequency of used Social Media shows that, $82.4 \%$ respondents use Social Media daily, while $17.0 \%$ of them use social media several times per week and other $0.6 \%$ of respondents use Social Media several times per month.

\section{DISCUSSION}

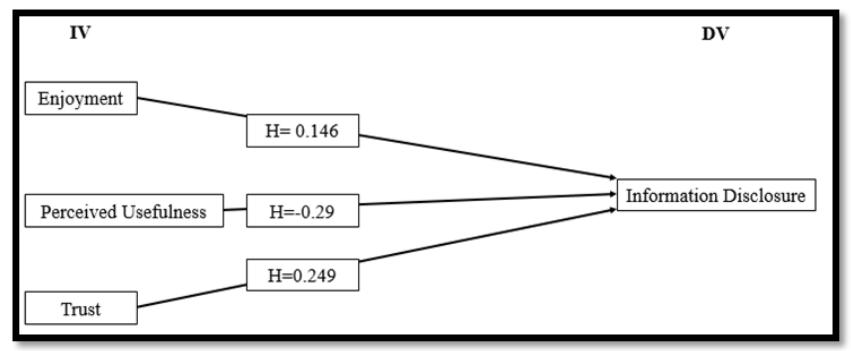

Figure 2: The relationship between variables

Correlation data defines the positive relationship between enjoyment and information disclosure in Social Media among teenagers in Malaysia with the $\mathrm{p}<.05$ and $\mathrm{r}=0.146$. It can be concluded there is a weak positive relationship between enjoyment and information disclosure in Social Media among teenagers in Malaysia. The finding demonstrates that when people feel enjoy to used Social Media, it will increase their information disclosure in Social Media (McKnight, Lankton and Trip, 2011). Based on the finding of this study, it was consistent with past literature by Krasnova (2009); Elmi, A. Iahad, and Ahmed (2013); McKnight, Lankton, and Tripp (2011). Therefore Hypothesis 1 is accepted. The results of this study have empirically shown that enjoyment and information disclosure in social media among teenagers were positive and had a relationship. Generally, respondents have agreed that enjoyment was a factor that influences them to disclose information in social media. Since nowadays, social media is one of the media for teenagers to express their feeling, when the teenager feels enjoy with social media. Eventually, it enhances them to disclose information in social media.

Next, the correlation value between Perceived Usefulness and Information Disclosure is $r=-0.029$ and $p$-value is .603 which is $p>.05$. It can be concluded that there is a weak negative relationship between perceived usefulness and information disclosure in Social Media among teenagers in Malaysia and that and between perceived usefulness and information disclosure is not significant. This study proves that, that the users of social media will increase the information disclosure in social media among teenagers. This indicates that there is a relationship between perceived usefulness and information disclosure and the findings are consistent with past literature by Sun, Wang, Shen, and Zhang (2015); Li and Sarathy (2007) since there has a relationship between perceived usefulness and information disclosure. Therefore Hypothesis 2 is accepted. The results of this study have empirically shown that perceived usefulness and information disclosure in social media among teenagers were negative and had a relationship. Generally, respondents have agreed that perceived usefulness was a factor that influences them to disclose information in social media. Perceived usefulness become the factor that influences information disclosure because when a teenager feels social media is useful and the risk of using social media is lower where they can communicate with others without any boundaries teenagers have the willingness to disclose their information in social media.

Lastly, there is a significant relationship exist between Trust and Information Disclosure since $\mathrm{p}<.05$ and $\mathrm{r}=0.249$. It can be concluded there is a weak positive relationship between trust and information disclosure in Social Media among teenagers in Malaysia. This study proves that, when people trust with their members in Social Media, it will enhance them to disclose the information in Social Media more. This indicates that there is a relationship between perceived usefulness and information disclosure and the findings was consistent with past literature by Elmi, A. Iahad, and Ahmed (2013); McKnight, Lankton, and Tripp (2011). Therefore Hypothesis 3 is accepted. The results of this study have empirically shown that trust and information disclosure in social media among teenagers were positive and had a relationship. Generally, respondents have agreed that trust

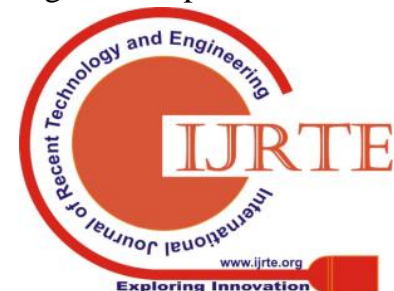


was a factor that influences them to disclose information in social media. Teenagers trust their members in social media because they know that their friend does not uses their information in a wrong way where the risk when disclosing information on social media is lower. Thus, trust is the factor that influences them to disclose information in social media.

In sum, the findings discussed above have helped the researcher to answer all of the research questions. Specifically, these findings have empirically answered and certified that factor of enjoyment, perceived usefulness and trust have a relationship with information disclosure in social media among teenagers in Malaysia.

In a nutshell, the entire hypotheses have a relationship between information disclosure. The highest relationship is between Trust and Information Disclosure with value 0.249. The lowest relationship is between perceived usefulness and information Disclosure with $\mathrm{r}=-0.029$.

\section{CONCLUSION}

This paper has investigated the factor that influences teenagers to disclose information is Social Media since Social Media nowadays teenagers are the largest group who used Social Media. From this research, it has been found that Enjoyment, Perceived Usefulness and Trust were the factors that enhance these teenagers to disclose their information such as email, picture and others in Social Media. Understanding the factors that would influence the Information Disclosure in Social Media among teenagers, assuredly it will assist the other researcher in designing the framework to promote further and additional research, especially on a dimension that affects the Information Disclosure in Social Media with a different population. Therefore, through this research, the other researcher will be able to know which factor that influence on the Information Disclosure in Social Media. Perhaps, the research framework developed will not only be tested at one school in Malaysia but likewise at another school.

\section{ACKNOWLEDGEMENTS}

The study was supported by a grant from the Dana Universiti Teknologi MARA, Cawangan Selangor (DUCS grant) - (600-UiTMSEL (PI. 5/4) (005/2018).

\section{REFERENCES}

1. Altman, I. (1975). The Environment and Social Behavior: Privacy, Personal Space, Territory, Crowding. Wadsworth Publishing Company. https://doi.org/10.2307/2065073

2. Babbie, E. R. (2010). The Practice of Social Research. Doing Quantitative Research in Education with SPSS. 2nd edition. London: SAGE Publications.

3. Bazarova, N. N., \& Choi, Y. H. (2014). Self-disclosure in social media: Extending the functional approach to disclosure motivations and characteristics on social network sites. Journal of Communication, 64(4), 635-657. https://doi.org/10.1111/jcom.12106

4. Buchwald, A., Letner, A., Urbach, N., \& EnterB-Fursteneck, M. v. (2017). Towards explaining the willingness to disclose personal self-tracking to service providers. 25th European Conference on Information Systems (ECIS) (hlm. 1-11). Portugal: Frounhoufer.

5. Chiu, C.-M., Hsu, M.-H., \& Wang, T. E. (2006). Understanding knowledge sharing in virtual communities: An integration of social capital and social cognitive theories. Decision Support System.

6. Coakes, S. J. (2013). SPSS: analysis without anguish: version 20 for Windows . Milton, Qld: John Wiley \& Sons.

7. Culnan, M. J., \& Armstrong, P. K. (1999). Information Privacy Concerns, Procedural Fairness, and Impersonal Trust: An Empirical Investigation.
Organization $\quad$ Science, $\quad 10(1)$

$104-115$.

https://doi.org/10.1287/orsc.10.1.104

8. Dancey, C., \& Reidy, J. (2004). Statistic without maths for phycology Using SPSS for windows. London.

9. Daud, M. (2014). Definasi Remaja. Didapatkan dari http://belia-malaysia.blogspot.my/2007/07/definisi-belia.html

10. David, F. (1989). An extended privacy calculus model for e-commerce transaction. Information System Research, 319-340.

11. Dienlin, T., \& Metzger, M. J. (2016). An Extended Privacy Calculus Model for SNSs: Analyzing Self-Disclosure and Self-Withdrawal in a Representative U.S. Sample. Journal of Computer-Mediated Communication, 21(5), 368-383. https://doi.org/10.1111/jcc4.12163

12. Dr Ong Beng Keat. (2017). Cyberbullying link to youth suicide in Malaysia. New Strait Times.

13. Elmi, A. H., A. Iahad, N., \& Ahmed, A. A. (2013). Factors influence self-disclosure amount in social networking sites. Journal of Information system research and innovation. Didapatkan December 2017

14. Guba, E. G. (1990). The Paradigm Dialog. New Bury Park.

15. Hart, J., Ridley, C., Taher, F., Sas, C., \& Dix, A. (2008). Exploring the Facebook Experience: A new approach to usability. Proceedings of NordiCHI. Sweden.

16. Heijden, H. v. (2004). User Acceptance of Hedonic Information Systems. MIS Quarterly, 695-704.

17. Jourard, S. M. (1971). Self-disclosure: An experimental analysis of the transparent self. New. New York.

18. Krasnova, H., \& Veltri, N. F. (2010). Privacy Calculus on social Networking Sites: Explorative Evidence from Germany and USA. Proceedings of the 43rd hawai International Conference on System Science. Hawaii.

19. Kaiser, H., \& Cerny, C. (1974). A study of a measure of sampling adequacy for factor-analytic correlation matrices. Mutivariate Behavioral Research, 43-47.

20. Krasnova, H., Kolesnikova, E., \& Gunther, O. (2009). "It won't Happen to Me!: Self-Disclosure in online social network. Self-Disclosure in Online Social Networks.

21. Kuhn, T. (1962). The structure of scientific revolutions. 3rd ed. Chicago: University of Chicago Press.

22. Laufer, R. S., \& Wolfe, M. (1977). Privacy as a Concept and a Social Issue: A Multidimensional Developmental Theory. Journal of Social Issues, 33(3), 22-42. https://doi.org/10.1111/j.1540-4560.1977.tb01880.x

23. Lewis, J. (1993). Multipoint scales: Mean and median differences and observed significance levels, International Journal of Human computer Interaction 383-392.

24. Li, H., \& Sarathy, R. (2007). Understanding Online Information Disclosure as a Privacy Calculus Adjusted by Exchange Fairness. International Conference on Information System (ICIS). Montreal.

25. Li, K., Wang, X., Li, K., \& Che, J. (2016). Information Privacy disclosure on social networking sites: An empirical investigation from social exchange. Nakai Business Review International, 282-300.

26. Marwick, A. E., \& Boyd, danah. (2011). I tweet honestly, I tweet passionately: Twitter users, context collapse, and the imagined audience. New Media \& Society, 13(1), 114-133. https://doi.org/10.1177/1461444810365313

27. Mesch, G. S. (2012). Is online Trust and Trust in Social Instituitions Associated with Online Disclosure of Identifiable Information Online? Computers in Human Behavior, 28, 1471-1477

28. McKnight, D., Lankton, N., \& Tripp, J. (2011). Social Networking Information Disclosure and Continuance Intention: A Disconnect. 44th Hawai International Conference on System Science. Manoa.

29. BIBLIOGRAPHY MCMC. (2016). Internet Users Survey 2016. Malaysian Communications and Multimedia Commission.

30. Pillay, S. (2017). Cyberbullying link to youth suicide. New Straits Times

31. Podsakoff, P., MacKenzie, S., \& Podsakoff, N. (2003). Common method biases in behavioral research: A critical review of the literature and recommended remedies. Journal of Applied Psychology, 879-903.

32. Raghavan, S. (2006). Blogs and Business Conversations. Journal of Creative Communications, 1, 285-295. https://doi.org/10.1177/097325860600100305

33. Sakeran, U., \& Bougie, R. (2013). Research Methods for Business: A Skill-Building Approach, 6th Edition. Colorado.

34. Simon, S. (2007). Cyber Victimization: School Experience of Malaysian Cyberbullied. Word Academy of Science, Engineering and Technology International Journal of Humanities and Social Science, 708-715. 
35. Sun, Y., Wang, N., Shen, X.-L., \& Zhang, J. X. (2015). Location information disclosure in location-based social network services: Privacy calculus, benefits structure and gender differences. Computer in Human Behavior, 278-292.

36. Svenja, B. (2016). Privacy Paradox: Factors influencing disclosure of personal information among German and Dutch Users.

37. Thye, L. L. (2017). On the Alert for Cyberbullying. Kuala Lumpur: The Start Online.

38. Veltri, N., Krasnova, H., \& Garah, W. E. (2011). Online Disclosure and Privacy Concern: a study of Moroccan and american facebook Users. Proceedings of the Seventeenth Americas Conference on Information System. Detroit, Michigan: Research Gate.

39. Zlatolas, L. N. (2015). Privacy antecedents for SNS self-disclosure: The case of Facebook. Computers in Human Behavior. 